\title{
Metabolic Effects of Exercise in Patients with Type IV Hyperlipoproteinemia
}

RUNE SANNERSTEDT, MD, PhD* SHAFEEK S. SANBAR, MD, PhD $\dagger$ and JAMES CONWAY, MD, PhD

Ann Arbor, Michigan
From the Clinical Physiology Unit, Department of Internal Medicine, University of Michigan Medical Center, Ann Arbor, Mich. This study was supported in part by grants from the Michigan Heart Association and from the National Institutes of Health (CD 00081). Manuscript received April 28, 1969, accepted November 7, 1969.

* Present address: A. B. Hăssle, Fack, Göteborg 5, Sweden.

$\dagger$ U. S. Army Medical Research and Nutrition Laboratory, Fitzsimons General Hospital, Denver, Colo.

Address for reprints: Dr. James Conway, Cardiovascular Training Program A-340, Veterans Administration Hospital, Washington, D. C. 20422.
Metabolic responses to $\mathbf{3 0}$ minutes of submaximal exercise were investigated in 11 healthy control subjects and 6 patients with type IV hyperlipoproteinemia (endogenous or essential hypertriglyceridemia). All subjects were male and ranged in age from 35 to 55 years. Before exercise they fasted overnight for at least 12 hours. The relative work performed, judged by the levels in heart rate and cardiac output on exercise, was comparable in the two groups, and the effects of exercise were qualitatively similar. Plasma glucose and triglyceride levels showed little change. Plasma concentration of cholesterol increased at the end of exercise by approximately 13 percent above control values compared to a concomitant increase in hematocrit of $\mathbf{3}$ percent. Plasma free fatty acid levels fell as exercise started and then returned to normal valves at the end of the $\mathbf{3 0}$ minutes of exercise; they then increased markedly after exercise but returned subsequently to control levels after $\mathbf{4 5}$ minutes.

In response to muscular exercise, therefore, both control subjects and patients with type IV hyperlipoproteinemia significantly increase plasma cholesterol concentration. Subjects with hyperlipoproteinemia appear to mobilize free fatty acids in a normal manner for energy purposes, and the excess release of free fatty acids during exercise is apparently not derived from the abundantly circulating triglycerides; the latter were not altered by submaximal exercise.

Lipids constitute an important fuel for metabolic processes. In human subjects and in animals, free fatty acid mobilization or lipolysis is enhanced during muscular activity, and adequate lipolysis plays a cardinal role in the maintenance of metabolic balance.,2 In normal human subjects, alterations in plasma lipid and glucose metabolism in response to submaximal exercise have been well documented. ${ }^{3}$ On the other hand, only limited information is available on the pattern of response of plasma lipids and glucose to submaximal exercise in patients with disorders of lipid metabolism.

In the present investigation, we have addressed ourselves to these questions: (1) How does the free fatty acid response of patients with type IV hyperlipoproteinemia (endogenous or essential hypertriglyceridemia) to submaximal exercise compare with that of subjects in a matched control group? (2) Do the abundantly circulating triglycerides of such patients contribute free fatty acids for oxidation during exercise? (3) Does exercise produce changes in plasma concentrations of cholesterol and glucose in these patients? 
This information is of theoretical interest in the elucidation of abnormal metabolic pathways in hyperlipoproteinemia and of practical importance in determining whether exercise favorably alters serum lipid concentrations. Hemodynamic and metabolic studies were conducted in 6 men with type IV hyperlipoproteinemia before, during and after a 30 minute submaximal exercise test, and the data were compared with those of subjects in a matched control group.

\section{Material and Methods}

Control subjects: Eleven men were recruited from the hospital staff on a volunteer basis. They all were healthy with no symptoms or signs of illness antecedant to this study. In 6 subjects, aged 30 to 54 years, complete hemodynamic and metabolic studies were performed. In the remaining 5 subjects, only changes in hematocrit and plasma cholesterol were determined before and after exercise.

Hyperlipoproteinemic subjects: Six men, aged 35 to 55 years, had type IV hyperlipoproteinemia (endogenous or essential hypertriglyceridemia), according to the classification of Fredrickson and Lees. ${ }^{4}$ Two patients had benign arterial hypertension, and a third had had renovascular hypertension cured by surgery. No patient had a history of myocardial infarction, angina pectoris or heart failure. At the time of the study, no patient was receiving antihyperlipidemic drugs, but 4 patients were on a diet consisting of 40 percent carbohydrates and 40 percent fat, half of which was unsaturated, for periods ranging from 2 to 36 months. All but 1 of these 4 patients responded to this regimen with a substantial fall in plasma triglyceride concentration; the average pretreatment level was $729 \mathrm{mg} / 100 \mathrm{ml}$ compared to the average level of $306 \mathrm{mg} / 100 \mathrm{ml}$ on the day of study. One patient was receiving chlorothiazide for hypertension.

Plan of study: All subjects were studied in the morning after having fasted and abstained from smoking overnight. They reported on their present amount of physical activity through an interview questionnaire. Catheters were inserted percutaneously into the left brachial artery and an antecubital vein.

After the patients had 30 minutes of recumbent rest, two blood samples were taken for analysis of free fatty acids, cholesterol, triglycerides and glucose in plasma. The intraarterial blood pressurc and heart rate were determined in all subjects, and the cardiac output in all but 1 patient. In 1 control subject the dye-dilution curve at rest was technically unsatisfactory and could not be used for calculation. The subjects were then transferred to a bicycle ergometer (AB Monark, Sweden), and another set of blood samples and determinations was obtained with the subjects resting on the bicycle. Subsequently, all subjects exercised for 30 minutes; the standardized work load was 450 $\mathrm{kg}-\mathrm{m} / \mathrm{min}$, except for 1 patient whose load was set at $300 \mathrm{~kg}-\mathrm{m} / \mathrm{min}$. Blood samples were taken after 10, 20
TABLE I

Age, Height and Weight of Six Male Control Subjects and Six Male Patients with Hyperlipoproteinemia (Mean \pm SEM)

\begin{tabular}{lrc}
\hline & $\begin{array}{c}\text { Control } \\
\text { Subjects }\end{array}$ & $\begin{array}{c}\text { Patients with } \\
\text { Hyperlipoproteinemia }\end{array}$ \\
\hline Age (yr) & $46.8 \pm 2.2$ & $42.8 \pm 3.0$ \\
Height (cm) & $176.0 \pm 3.1$ & $179.0 \pm 2.3$ \\
Weight (kg) & $78.8 \pm 5.1$ & $86.1 \pm 6.5$ \\
\hline
\end{tabular}

and 30 minutes of exercise; the cardiac output was measured during the last minute. After exercise the subjects were returned to the recumbent position, and blood samples were drawn at $3,7,15,30,45$ and 75 minutes. The cardiac output was determined 8 and 24 minutes after the exercise period.

Laboratory methods: Arterial blood samples were obtained throughout the procedure; they were chilled in ice water, and plasma was separated. Glucose was determined by the method of Somogyi and Nelson. ${ }^{5} \mathrm{~A}$ portion of plasma was stored at $-15 \mathrm{C}$ for free fatty acid analysis at a later date by the method of Dole and Meinertz. ${ }^{6}$ Plasma cholesterol and triglycerides were analyzed by the methods of Connerty et al. ${ }^{7}$ and Van Handel and Zilversmit, ${ }^{8}$ respectively.

The principles used for recording the intraarterial blood pressure and cardiac output have been presented in detail elsewhere. ${ }^{9}$

Student's $t$ test was used to test differences between means with a $P$ level of $<0.05$ being chosen to indicate statistical significance.

\section{Results}

Comparison of data obtained in 6 control and 6 hyperlipoproteinemic subjects: The two groups of male subjects had similar mean values for age, height and body weight (Table I). There were no consistent differences in the amount of daily physical activity, as determined by the interview form.

Table II shows that the mean concentrations of plasma glucose, free fatty acid and cholesterol in the fasting state were slightly higher in the hyperlipo-

TABLE II

Concentrations of Plasma Glucose and Lipids in Fasting State (Mean \pm SEM)

\begin{tabular}{lccc}
\hline & $\begin{array}{c}6 \text { Control } \\
\text { Subjects }\end{array}$ & $\begin{array}{c}6 \text { Patients with } \\
\text { Hyperlipoproteinemia }\end{array}$ & $\begin{array}{c}P \\
\text { Value }\end{array}$ \\
\hline $\begin{array}{c}\text { Glucose } \\
(\mathrm{mg} / 100 \mathrm{ml})\end{array}$ & $86 \pm 4$ & $92 \pm 3$ & NS \\
$\begin{array}{c}\text { Free fatty acids } \\
(\mu \mathrm{Eq} / \text { liter })\end{array}$ & $760 \pm 97$ & $810 \pm 95$ & NS \\
$\begin{array}{c}\text { Cholesterol } \\
(\mathrm{mg} / 100 \mathrm{ml})\end{array}$ & $198 \pm 17$ & $234 \pm 24$ & NS \\
$\begin{array}{c}\text { Triglycerides } \\
(\mathrm{mg} / 100 \mathrm{ml})\end{array}$ & $91 \pm 14$ & $298 \pm 78$ & $<0.05$ \\
\hline
\end{tabular}

NS $=$ not significant 
TABLE III

Changes in Heart Rate Submaximal Exercise (Mean \pm SEM)

\begin{tabular}{lrc}
\hline & $\begin{array}{c}6 \text { Control } \\
\text { Subjects }\end{array}$ & $\begin{array}{c}\text { 6 Patients with } \\
\text { Hyperilpoproteinemla }\end{array}$ \\
\hline $\begin{array}{l}\text { Before exercise } \\
\quad \text { Recumbent }\end{array}$ & $68 \pm 3$ & $72 \pm 4$ \\
$\quad \begin{array}{l}\text { Sitting } \\
\text { At } 30 \text { minutes of exercise }\end{array}$ & $74 \pm 4$ & $75 \pm 5$ \\
After exercise (recumbent) & $134 \pm 8$ & $130 \pm 8$ \\
$\quad 8$ minutes & $88 \pm 3$ & $87 \pm 7$ \\
25 minutes & $76 \pm 4$ & $81 \pm 7$ \\
\hline
\end{tabular}

proteinemic subjects than in the control subjects. However, the differences were not statistically significant. Serum triglyceride concentration, on the other hand, was significantly higher in the hyperlipoproteinemic than in the control subjects; paper lipoprotein electrophoresis revealed marked hyper-prebeta-lipoproteinemia in the patient groups.

Mean changes in heart rate, arterial pressure and cardiac output after submaximal exercise were similar in both groups of subjects (Tables III to V). At 30 minutes of exercise, the heart rate increased by approximately 80 percent above control values (Table III). After 8 minutes of recumbency after exercise, the heart rate was only slightly above control values, and after 25 minutes, it was back to control values. One subject in each group had an exercise heart rate exceeding 150 beats/min. The mean arterial blood pressure increased at 30 minutes of exercise by approximately 20 percent above control values and fell to below control values after exercise (Table IV). The cardiac output was about twice the control values at 30 minutes of exercise; after exercise it decreased toward control values.

The concentrations of plasma glucose, free fatty acids, triglycerides and cholesterol have been noted in Table II. Alterations in these substrates during and after exercise are shown in Figures 1 to 4 , with the mean fasting level of concentration taken as zero. Plasma glucose response during exercise was variable in both groups of subjects but tended to increase gradually among patients with hyperlipoproteinemia
TABLE IV

Changes in Mean Arterial Pressure (mm Hg) After Submaximal Exericise (Mean \pm SEM)

\begin{tabular}{lcc}
\hline & $\begin{array}{c}6 \text { Control } \\
\text { Subjects }\end{array}$ & $\begin{array}{c}6 \text { Patients with } \\
\text { Hyperlipoproteinemia }\end{array}$ \\
\hline Before exercise & & \\
$\quad$ Recumbent & $101 \pm 8$ & $110 \pm 12$ \\
$\quad$ Sitting & $119 \pm 5$ & $114 \pm 12$ \\
At 30 minutes of exercise & $136 \pm 4$ & $131 \pm 13$ \\
After exercise (recumbent) & $94 \pm 6$ & $102 \pm 10$ \\
$\quad 8$ minutes & $95 \pm 6$ & $96 \pm 9$ \\
\hline
\end{tabular}

(Fig. 1). After exercise, the concentration of plasma glucose decreased to, and slightly below, control values. However, in both groups, the differences between the concentrations of plasma glucose during and after exercise and those of the control state were not statistically significant.

Before exercise, transfer from a recumbent position to sitting on the bicycle resulted in a slight decrease in plasma free fatty acid concentration in the control subjects and a moderate increase in those with hyperlipoproteinemia (hypertriglyceridemia) (Fig. 2). The change in plasma concentration of free fatty acids during exercise was similar both qualitatively and quantitatively in the two groups, showing a moderate initial decrease during the first two thirds of the exercise period and subsequently a gradual return toward control values. After exercise was stopped, there was a prompt increase in plasma free fatty acids, a peak of similar height being reached within 8 minutes in both groups of subjects. Plasma free fatty acid concentration returned to control values 45 minutes after the end of exercise.

Transfer from a recumbent position to sitting on the bicycle produced a significant increase in plasma triglyceride concentration in the subjects with hyperlipoproteinemia (hypertriglyceridemia), but not in the control subjects (Fig. 3). However, both during and after exercise, plasma triglyceride values were not significantly different from the values in the recumbent period before exercise.

Finally, the changes in plasma concentration of

TABLE V

Changes in Cardiac Output (liters/min) After Submaximal Exercise (Mean \pm SEM)

\begin{tabular}{|c|c|c|c|c|c|}
\hline \multirow[b]{2}{*}{ Subjects } & \multicolumn{2}{|c|}{ Before Exercise } & \multirow{2}{*}{$\begin{array}{l}\text { At } 30 \text { Minutes } \\
\text { of Exercise }\end{array}$} & \multicolumn{2}{|c|}{$\begin{array}{l}\text { After Exercise } \\
\text { (Recumbent) }\end{array}$} \\
\hline & Recumbent & Sitting & & 8 Minutes & 25 Minutes \\
\hline 6 control subjects & $\begin{aligned} 4.70 & =0.07 \\
\text { no. } & =5\end{aligned}$ & $\begin{aligned} 5.02 & =0.45 \\
\text { no. } & =5\end{aligned}$ & $\begin{aligned} 11.48 & \pm 0.33 \\
\text { no. } & =6\end{aligned}$ & $\begin{aligned} 6.42 & \pm 0.52 \\
\text { no. } & =6\end{aligned}$ & $\begin{aligned} 5.35 & \pm 0.49 \\
\text { no. } & =6\end{aligned}$ \\
\hline $\begin{array}{l}6 \text { patients with } \\
\text { hyperlipoproteinemia }\end{array}$ & $\begin{aligned} 6.20 & =0.35 \\
\text { no. } & =5\end{aligned}$ & $\begin{aligned} 4.62 & =0.32 \\
\text { no. } & =5\end{aligned}$ & $\begin{aligned} 10.94 & =0.84 \\
\text { no. } & =5\end{aligned}$ & $\begin{aligned} 6.70 & \pm 0.62 \\
\text { no. } & =4\end{aligned}$ & $\begin{aligned} 5.76 & \pm 0.36 \\
\text { no. } & =5\end{aligned}$ \\
\hline
\end{tabular}


Figure 1. Response of plasma glucose to physical exercise. Mean values $\pm S$.E. for changes from the initial resting level on exercise and in the immediate post-exercise period.

Figure 2. Response of plasma concentration of free fatty acid to physical exercise. Mean values \pm SEM for changes from the initial resting level on exercise and immediately after exercise period. "denotes sig. nificant $(P<0.05)$ difference in response between control subjects and patients with hypertriglyceridemia.

Figure 3. Response of plasma concentration of triglyceride to physical exercise. Mean values \pm SEM for changes from the initial resting level on exercise and immediately after exercise. *denotes significant $(P$ $<0.05$ ) difference in response between control subjects and patients with hypertriglyceridemia.
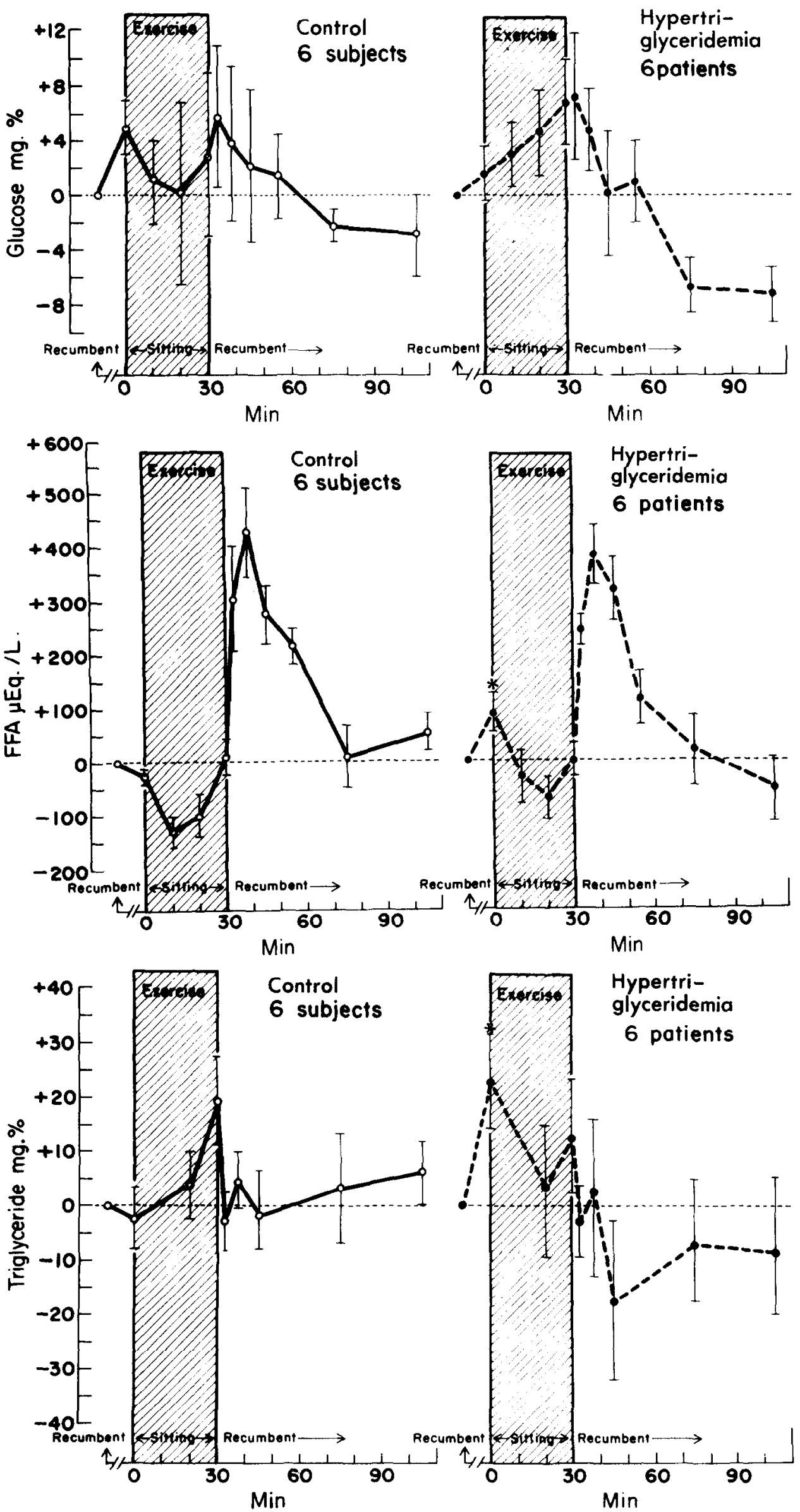


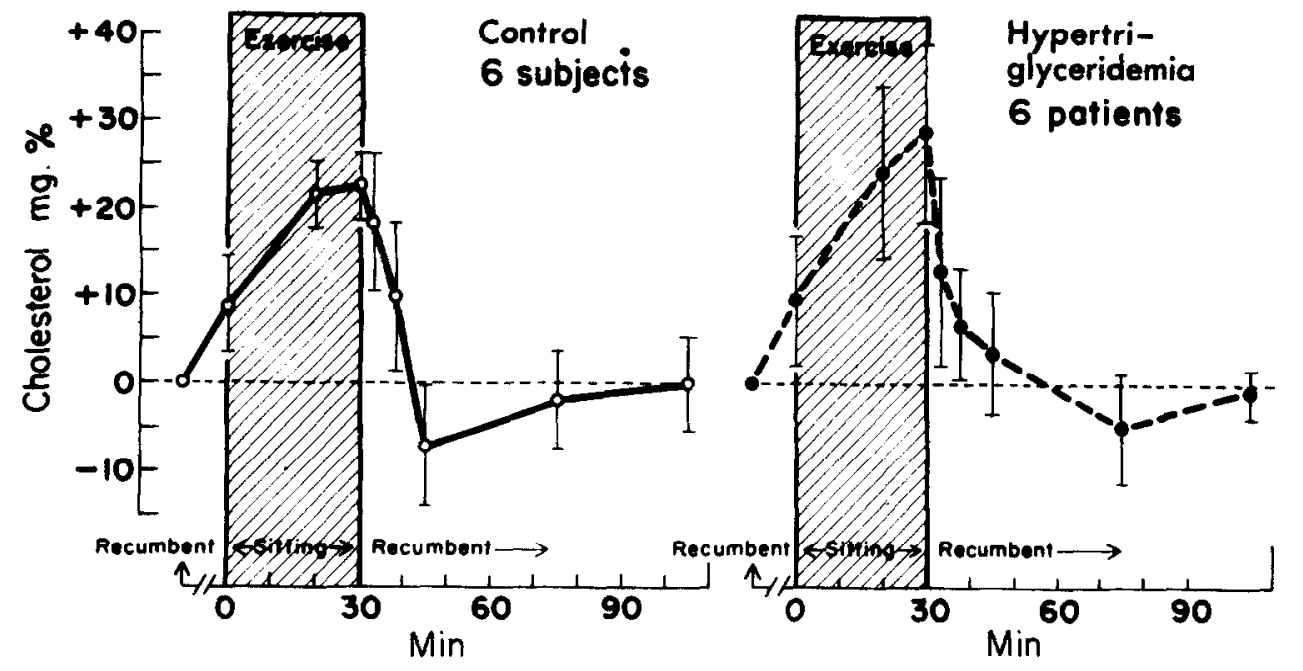

Figure 4. Response of plasma cholesterol levels to physical exercise. Mean values $\pm S E$ for changes from the initial resting level on exercise and immediately after exercise. cholcsterol after exercise were similar in both groups (Fig. 4). After the subjects had transferred to the bicycle, plasma cholesterol values increased slightly. Exercise produced in both groups a further increment in plasma cholestcrol levels, with a peak of about 12 percent above recumbent values occurring at the end of exercise. Plasma cholesterol levels promptly returned toward the recumbent values before exercise after exercisc was stopped.

Comparison of changes in hematocrit and plasma cholesterol values after exercise: In the 5 remaining control subjects, both hematocrit and plasma cholesterol concentrations were determined before and at the end of exercise and 15 minutes after exercise. Both values increased at 30 minutes of exercise and returned toward control levels 15 minutes after exercise (Table VI). However, although the mean ( $\left.\pm_{\text {SEM }}\right)$ percent increase in plasma cholesterol was $12.7( \pm 4.5)$ above control values, the hematocrit changed only from 43.4 to 46.1 percent, suggesting that hemoconcentration is apparently not the sole cause of the increase in plasma cholesterol during exercise:

\section{Discussion}

These findings demonstrate that the metabolic pattern of response of fuel substrates to a standard submaximal exercise in patients with type IV hyperlipoproteinemia (endogenous or essential hypertriglyceridemia) is similar to that of control subjects. Both control and hyperlipoproteinemic subjects were men with similar weight, height and age ranges. Furthermore, the relative work performed by both groups of subjects was comparable, as judged by changes in heart rate and cardiac output after exercise.

Plasma glucose: Plasma glucose concentration in this study showed a tendency to a biphasic variation, with a diminution after exercise. However, these changes after exercise were not statistically significant in either the control subjects or those with hyperlipoproteinemia. Our data in the control subjects is in accord with those of others ${ }^{10-13}$ who found no significant alteration in plasma glucose concentration in normal subjects during and immediately after short periods of submaximal exercise. However, although plasma glucose concentration is not changed by exercise, glucose turnover, determined isotopically, has been shown to increase slowly, reaching a peak at the end of exereise. ${ }^{14}$ It is therefore conceivable that glucose turnover might have been altered in our subjects during exercise.

Plasma free fatty acids: The pattern of response of plasma free fatty acid concentration in both groups

TABLE VI

Changes in Hematocrit and Plasma Cholesterol Concentration After Submaximal Exercise (Mean \pm SEM)

\begin{tabular}{|c|c|c|c|c|c|c|}
\hline \multirow{2}{*}{$\begin{array}{l}\text { Normal } \\
\text { Subjects }\end{array}$} & \multicolumn{2}{|c|}{ Before Exercise } & \multicolumn{2}{|c|}{ At 30 Minutes of Exercise } & \multicolumn{2}{|c|}{15 Minutes After Exercise } \\
\hline & Het & Chol & Het & Chol & Het & Chol \\
\hline 1 & 41.0 & 201 & 43.0 & 219 & 41.0 & 198 \\
\hline 2 & 42.0 & 140 & 45.0 & 155 & 43.0 & 141 \\
\hline 3 & 41.5 & 195 & 45.0 & 202 & 43.0 & 196 \\
\hline 4 & 47.0 & 151 & 47.0 & 166 & 47.0 & 152 \\
\hline 5 & 45.0 & 200 & 50.5 & 260 & 49.0 & 233 \\
\hline Mean & 43.4 & 177 & 46.1 & 200 & 44.6 & 184 \\
\hline \pm SEM & 1.2 & 13 & 1.3 & 19 & 1.5 & 17 \\
\hline
\end{tabular}

Chol = cholesterol $(\mathrm{mg} / 100 \mathrm{ml}) ; \mathrm{Hct}=$ hematocrit $(\%)$. 
of subjects were, of course, similar and clearly depicted the different phases of plasma free fatty acids after exercise, as described by Carlsson et al. ${ }^{3}$ During the first 10 to 15 minutes of exercise, there is a reduction in the concentration of plasma free fatty acids. This circulatory phase, during which the cardiovascular adjustments to exercise occur rapidly, is associated with increased efflux of free fatty acids from plasma. After about 20 minutes of exercise, plasma free fatty acid concentration returns to control levels or may be higher due to enhanced influx of free fatty acids into the plasma. During this metabolic phase, the glycerol concentration increases, thus indicating enhanced lipolysis of triglycerides, presumably from adipose tissue. Finally, after exercise is stopped, plasma free fatty acid concentration rapidly increases to a peak about 10 minutes after the end of exercise and subsequently returns toward control level within $1 / 2$ to 1 hour. During this postexercise recovery phase, concentrations of glycerol, unlike those of free fatty acids, abruptly fall toward control values within a few minutes after exercise is stopped.

Plasma triglycerides: During the metabolic phase, the turnover rate of plasma free fatty acids is increased.1.15 Further, between about 75 percent (trained subjects) and 50 percent (untrained subjects) of the free fatty acid flux through plasma is immediately oxidized. ${ }^{115}$ However, despite a respiratory quotient of 0.75 , only 25 to 50 percent of the carbon dioxide in expired air could be derived from immediately metabolized plasma free fatty acids. This indicates that lipid sources other than plasma free fatty acids must have been used to generate energy for muscle work. Since plasma concentration of triglycerides in this study remained unaltered in both groups of subjects after exercise, circulating triglycerides do not appear to be utilized to a great extent as a source of fuel during muscle work, nor do they seem to be hydrolyzed intravascularly to provide free fatty acids. However, as with plasma glucose, concentration or absence of change in plasma concentration of triglycerides does not necessarily negate changes in triglyceride turnover during exercise. More data are needed to elucidate this matter.

The exercise responses were similar in both control and hyperlipoproteinemic subjects; however, the plasma free fatty acid and triglyceride levels differed in the two groups after the transfer from the recumbent to the sitting position. The increase in subjects with hyperlipoproteinemia, compared to the slight decrease in control subjects, may be attributed to the different reaction of the cardiac output to change in position. Patients with hyperlipoproteinemia, unlike the control subjects, had a significant decrease in cardiac output on transfer from the recumbent to the sitting position.

Abnormalities in response of free fatty acids to exercise have been reported in other metabolic disorders. Patients with newly diagnosed diabetes of juvenile or adult onset responded to an exercise test by a rapid and more marked increment in plasma free fatty acids, which also persisted longer than in control subjects. ${ }^{13,16}$ In those diabetic subjects, plasma triglyceride concentration did not change after exercise, and it was presumed that the higher concentration of plasma free fatty acids in diabetic patients resulted from augmented lipolysis of adipose tissue. Unlike diabetic patients, obese subjects have an impaired capacity to mobilize free fatty acids in response to submaximal exercise of short duration. However, no impairment of free fatty acid mobilization was observed in obese subjects during prolonged and relatively light exercise. ${ }^{18}$ Our study indicates that, unlike diabetic and obese subjects, patients with type IV hyperlipoproteinemia have a normal lipolytic response to exercise despite the ill defined basic lipid abnormality that leads to the hyperlipoproteinemia in these patients.

Plasma cholesterol: Finally, our study shows that plasma cholesterol concentration increases during exercise in both control and hyperlipoproteinemic subjects. This is in keeping with findings in normal subjects reported by other investigators. ${ }^{19-21}$ The percent change in plasma cholesterol was greater than that of hematocrit, thus suggesting that hemoconcentration itself probably cannot explain all the increase in plasma cholesterol levels. As yet, we have no adequate explanation for this increase, although the "stress" of exercise may in some way be a contributing factor. It is interesting that plasma cholesterol promptly returned to pre-exercise values after cessation of exercise and return to the recumbent position.

\section{References}

1. Havel RJ, Naimark A, Borchgrevink CF: Turnover rate and oxidation of free fatty acids of blood plasma in man during exercise: Studies during continuous infusion of palmitate-1-C14. J Clin Invest 42:105-463, 1963

2. Paul P, Issekutz B Jr: Role of extramuscular energy sources in the metabolism of the exercising dog. J Appl Physiol 22:615-622, 1967

3. Carlsson LA, Boberg J, Högstedt B: Some physiological and clinical implications of lipid mobilization from adipose tissue, chap 63, in Handbook of Physiology, sec-

tion 5, Adipose Tissue (Renold AE, Cahill GF Jr, ed). Washington, DC, American Physiological Society, 1965

4. Fredrickson DS, Lees RS: Familiar hyperlipoprotein emia, chap 23, in The Metabolic Basis of Inherited Disease (2nd edition) (Stanbury JB, Wyngaarden JB, Fredrickson DS, ed). New York, Blakiston Division, McGraw-Hill, 1966

5. Nelson N: A photometric adaptation of the Somogyi method for the determination of glucose.

J Biol Chem 153:375-380, 1944 
6. Dole VP, Meinertz H: Microdetermination of long-chain fatty acids in plasma and tissues. J Biol Chem 235:2595-2599, 1960

7. Connerty HV, Briggs AR, Eaton EH Jr: Simplified determination of lipid components of blood serum. Clin Chem 7:37-53, 1961

8. Van Handel E, Zilversmit DB: Micromethod for the direct determination of serum triglycerides. J Lab Clin Med 50:152-157, 1957

9. Julius S, Amery A, Whitlock LS, et al: Influence of age on the hemodynamic response to exercise. Circulation 36:222-230, 1967

10. Caristen A, Hallgren B, Jagenburg R, et al: Arterial concentrations of free fatty acids and free amino acids in healthy human individuals at rest and at different work loads. Scand J Clin Lab Invest 14:185-191, 1962

11. Reichard GA, Issekutz B Jr, Kimbel P, et al: Blood glucose metabolism in man during muscular work. J Appl Physiol 16:1001-1005, 1961

12. Karlefors T: Circulatory studies during exercise with particular reference to diabetics.

Acta Med Scand 180: suppl 449:3-18, 1966

13. Carlström S: Studies on fatty acid metabolism in diabetics during exercise. V. Plasma concentration of free fatty acids and glycerol in newly diagnosed, adult diabetics during exercise.

Acta Med Scand 182:363-376, 1967
14. Issekutz B Jr, Miller HI, RodahI K: Lipid and carbohydrate metabolism during exercise. Fed Proc 25:1415-1420, 1966

15. Friedberg SJ, Harlan WR Jr, Trqut DL, et al: The effect of exercise on the concentration and turnover of plasma nonesterified fatty acids. J Clin Invest 39:215-220, 1960

16. Carlström S: Studies on fatty acid metabolism in dia. betics during exercise. 1. Plasma free fatty acid con. centration in juvenile, newly diagnosed diabetics during exercise. Acta Med Scand 181:609-621, 1967

17. Klein RF, Troyer WG, Back KW, et al: Lipid mobiliza. tion in lean and obese subjects. Ann NY Acad Sci 131:662-672, 1965

18. Issekutz B Jr, Bortz WM, Miller HI, et al: Plasma free fatty acid response to exercise in obese humans. Metabolism 16:492-502, 1967

19. Naughton J, Balke B: Physical working capacity in medical personnel and the response of serum choles. terol to acute exercise and to training. Amer J Med Sci 247:286-292, 1964

20. Wood P, Schlierf G, Kinsell L: Plasma free oleic and palmitic acid levels during vigorous exercise. Metabolism 14:1095-1100, 1965

21. Naughton J, McCoy JF: Observations on the relation. ship of physical activity to the serum cholesteral concentration of healthy men and cardiac patients. J Chronic Dis 19:727-733, 1966 